\title{
The Effect of Trainee Characteristics and Organizational Environment on Individual Performance for Effective e-learning Context
}

\author{
Zakariya Belkhamza \\ Faculty of Business, Economics and Accountancy, \\ Universiti Malaysia Sabah \\ Kota Kinabalu, Malaysia \\ zakariya@ums.edu.my
}

\author{
Muhammad Madi Bin Abdullah \\ Asia Graduate School of Business \\ UNITAR International University \\ Selangor Darul Ehsan, Malaysia \\ Drmuhdmadi@gmail.com
}

\begin{abstract}
The emerging development of information technologies has significantly contributed to the learning organization enhancement, in which many organizations still find a great challenge to fully optimize the use of e-learning by their employees in order to enhance their individual performance. The objective of this paper is to investigate what factors determine an affective training performance which leads to high individual performance. Drawing from the self-determination and institutional learning theories, trainee characteristics and organizational environment constructs were determined to investigate whether they have an impact on the individual performance of the employees. Data from 203 employees in private sector in the Sabah state of Malaysia was used to test the research hypotheses. Results show that all variables were found to have positive relationship with individual performance. The research provides a significant insight and better understanding on how organizations better utilize the e-learning environment to enhance the learning process of their employees.
\end{abstract}

Keywords-e-learning; learning organization; trainee characteristics; organizational environment; individuation performance.insert.

\section{INTRODUCTION}

E-learning and online training programs have recently become an important method for organizations to facilitate the learning process to their employees. These e-learning initiatives are subjected to a rapid rate of technological change [1]. However, due to these technological fluctuations, the diversity of individual learning styles of employees become vulnerable to these fluctuations. This debate shows that a gap between the effectiveness of both settings still exists in the literature [2]. The question whether these learning programs actually change employees' behavior and enable them for a maximum potential remains crucial. Although knowledge can be learned by participating in e-learning programs, it is still arguable whether the outcome can help improve the work performance [3]. Therefore, the objective of this paper is to investigate what factors could affect employee's performance when using e-learning. The paper further investigates how good training performance will lead to high performance of employees.

\section{CONCEPTUAL DEVElopMent}

The performance of an employee as an individual is an important building wedge of an organization. Training programs have been widely used in many organizations for the purpose of enhancing employees' knowledge. The organizational learning is not an effort of just one or two individual's effort; but a collective effort of all members of the organization who contribute toward the organizational performance.

E-learning encompasses the delivery of learning through purely digital technology using the Internet or private networks. It often refers to various platforms and applications such as web-based learning, computer-based learning and digital collaboration. Recent developments in learning theories such as constructivism focus on the affective domain of learning; and how to enhance internal priorities and drivers of the learner toward a full engagement with the e-learning experience [4]. From the literature, it was found that two dimensions are less studied under this theoretical context. The first dimension is the trainee characteristics, which encompass two variables, motivation and self-efficacy, while the second dimension is the organizational environment, which consists of senior support and continuous learning culture.

\section{A. Trainee Characteristics}

Trainee characteristics are the personal features related to the learning process during the e-learning experience, and are difficult to regulate without a direct involvement from the trainee himself. Derived from the self-determination theory [5], two variables are introduced in this research: trainee motivation and self-efficacy.

Motivation is defined as the degree to which the learner is willing to make efforts to improve his or her performance of training and work. This positive response is regularly related to improvement of their work performance after the training [6]. Moreover, self-efficacy is defined as someone's beliefs about his or her capabilities to produce and execute the courses of action to handle a situation [7]. Previous studies also confirmed that the higher the trainee's self-efficacy 
towards the e-learning, the higher their learning performance [2]. Therefore, it is hypothesized that:.

H1: $_{1}$ Motivation toward e-learning is positively associated with individual performance.

\section{$\mathrm{H}_{2}$ : Self-efficacy is positively related to individual performance.}

\section{B. Organizational Environment}

Following the institutional learning theory put forward by [8], the habitual use of practices within the organization, such as ways of supervisor' support, become the structural properties of the organization. The interaction between senior managers and employees facilitate more knowledge sharing through the e-learning activities [9]. In this paper, this organizational environment is measured using two variables: senior support and continuous learning culture.

Senior Management support is the attribute formed in the organization that induces managers to lend assistance, and countenance to their subordinates [10], [11]. Previous studies confirmed that the more learners receive support from management regarding e-learning, the more their e-learning effectiveness is increased and observed [6]. Continuous learning culture however is the design of a challenging work responsibility schedule to develop employees' potential, fully compensating for self-developing effort, and emphasizing the improvement and renovation of the working environment [12]. Previous evidence also shows that continuous learning culture has significant impacts on training and application rate [12],[6]. Therefore, it is hypothesized that:

$\mathrm{H}_{3}$ : Senior management support is positively related to individual performance.

$H_{4}$ : Continuous learning culture is positively related to individual performance.

\section{The Mediating Effect of Training Performance}

The assessment of the training program itself has been noted to be an important process for the impact of the individual involved in the e-learning initiatives. Past studies have focused on measuring trainee reactions to the training program and the degree of learning from the program [12]. Because of the importance of the training performance, this study suggests that training performance will mediate the relationship between e-learning factors and individual performance. Therefore, it is hypothesized that:

H5: Training performance mediates relationship between training characteristics and organizational environments and individual performance.

\section{RESEARCH METHOD}

\section{A. Data Collection Method}

The target population of this cross-sectional study was full time employees in private firms who have experienced the use of e-learning in their workplace for at least one in the past six months. The target sample was employees working in the private sector with large firms as most of these firms have already adopted e-learning systems for their training and development. In order to test the research hypotheses, a selfadministered questionnaire was developed, composed of measures taken directly or adapted from previous studies.

\section{RESUlts}

250 questionnaires were distributed. However, only 211 initial responses were received. Out of these, 203 valid responds were considered for the final analysis, which makes the response rate to $81.2 \%$. In order to examine the reliability of the variables, Cronbach's alpha was computed. Table 2 illustrates that all measures have acceptable levels of reliability values. The values are all above 0.93 which is above the threshold of 0.7. Discriminant and convergent validity were both examined using factor analysis with a Varimax rotation. Results show that all items were significantly loaded on their respective factors, indicating adequate discriminant validity. Therefore, all variables demonstrated adequate reliability, convergent validity and discriminant validity

\section{A. Hypothesis Testing}

Multiple regression analysis was used to investigate the relationship between the variables. Results of this analysis are illustrated in Table 5. In the first hypothesis $\mathrm{H}_{1}$, the relationship was found to be statistically significant $(\beta=0.633$, $\mathrm{p}<0.01$ ). Therefore, $\mathrm{H}_{1}$ was supported. $\mathrm{H}_{2}$ was also supported as self-efficacy was found to have a positive relationship with individual performance $(\beta=0.702, \quad p<0.01)$. The third relationship was also significant $(\beta=0.722, \mathrm{p}<0.01)$. Hence, $\mathrm{H}_{3}$ was supported. Lastly, contiguous leaning culture was also found to be positively related to individual performance, $(\beta=0.737, \quad \mathrm{p}<0.01)$, which leads us to accept the final hypothesis $\mathrm{H}_{4}$.

TABLE I. Multiple REgRESSION ANALYSIS

\begin{tabular}{|c|l|c|c|c|}
\hline DV & IV & $(\boldsymbol{\beta})$ Beta & t-value & significant \\
\hline $\begin{array}{c}\text { Individual } \\
\text { Performance }\end{array}$ & & \multicolumn{3}{|l|}{} \\
\hline & Motivation & 0.633 & 11.593 & 0.00 \\
\hline & Self-Efficacy & 0.702 & 13.99 & 0.00 \\
\hline & $\begin{array}{l}\text { management } \\
\text { support }\end{array}$ & 0.722 & 14.806 & 0.00 \\
\hline & $\begin{array}{l}\text { Continuous } \\
\text { Learning } \\
\text { Culture }\end{array}$ & 0.737 & 15.452 & 0.00 \\
\hline \multicolumn{2}{|c|}{$\mathrm{R}^{2}=0.615$} & & \multicolumn{2}{|c|}{ Sig F Change $=.000$} \\
\hline \multicolumn{2}{|c|}{ F Value $=78.927$} & &
\end{tabular}

B. The Meditating effect

The mediating effect of Training performance in $\mathrm{H}_{5}$ was tested using a mediation analysis process suggested by [13]. This analysis estimates the size of an indirect effect of $\mathrm{X}$ on $\mathrm{Y}$ through a single mediator $\mathrm{M}$ and computes both normal theory and bootstrap approaches for inference. The variable is found 
to mediate the interval range if does not contain a 0 between the lower limit (LL) and the upper limit (UL) [13]. Following this analysis, all mediating effects of training performance was not found to straddle a 0 within the interval range at the $95 \%$ confidence as illustrated in Table 6. Therefore, hypothesis $\mathrm{H}_{6}$ is accepted.

TABLE II. THE MEDIATING EFFECT

\begin{tabular}{|c|c|c|c|c|}
\hline & Effect & SE(boot) & LLCI & ULCI \\
\hline Motivation & .5651 & .0598 & .4572 & .6979 \\
\hline Self-efficacy & .1792 & .0824 & 0.216 & .3460 \\
\hline $\begin{array}{c}\text { Management } \\
\text { support }\end{array}$ & .1959 & .0876 & 0.557 & .4048 \\
\hline $\begin{array}{c}\text { Continuous } \\
\text { learning culture }\end{array}$ & .3789 & .0715 & .2399 & .5284 \\
\hline
\end{tabular}

\section{DISCUSSION AND CONCLUSION}

The first hypothesis which posited that there is a positive relationship between motivation and individual performance was supported, indicating that motivation toward using elearning does have an impact on individual performance. This result confirms the previous findings but significantly validate this relationship in the e-learning context. This study also confirmed that self-efficacy has a positive relationship with individual performance in which this result joins and confirms previous research [6]. The third hypothesis finding provides clear indication for top management to continuously provide support to their employees and improve their knowledge using e-learning. These findings are consistent with previous studies on the same context [6]. The last hypothesis result indicates that it is necessary for companies nowadays to realize how important continuous learning culture is to their employees. Organizational environment with all-encompassing elements create and infuse the learning culture among employees, which in turn have an impact on the employees' respective performance [10]. The content quality of training is crucial to the success of the e-learning program.

This study contributes to the literature by providing a better understanding on how to improve the individual performance of learner in the e-learning context. The research findings provide valuable information as guidelines to improve and enhance the content of e-learning materials.
Findings may assist organizations and managers to improve their employees' performance by looking at the trainee characteristics and organizational environment. Future studies may also investigate the framework in the public sector and other industries to further provide a clear insight on the results.

\section{References}

[1] T.J. McGill , Klobas, J. E., \& Renzi, S. “ Critical success factors for the continuation of elearning initiatives" The Internet and Higher Education, Vol. 22, pp. 24-36. 2014. http://dx.doi.org/10.1016/j.iheduc.2014.04.001.

[2] C. Tsai, C.-C., Chuang, S.-C., Liang, J.-C., \& Tsai, M.-J. "Self-efficacy in Internet-based Learning Environments: A Literature Review" Educational Technology \& Society, Vol. 14 No. 4, pp. 222-240. 2011.

[3] L. Patel, " ASTD State of the industry report 2010". Alexandria, VA: American Society for Training \& Development. 2010.

[4] D.H. Schunk, “ Learning Theories: An Educational Perspective". Pearson; 7th Revised edition. 2015.

[5] E. L. Deci, \& R.M. Ryan, "Handbook of self-determination research". Rochester, NY: University of Rochester Press.2002.

[6] H. Lim, Sang-Gun Lee, S.H, \& Kichan Nam, K. "Validating E-learning factors affecting training effectiveness". International Journal of Information Management, Vol. 27, pp. 22-35. 2007.

[7] A. Bandura, A. "Self-efficacy". In V. S. Ramachaudran (Ed.), Encyclopedia of human behavior . 1994. Vol. 4, pp. 71-81. New York: Academic Press.

[8] W.J. Orlikowski, "The duality of technology: Rethinking the concept of technology in organization". Organization Science, Vol. 3, No. 3, pp. +398-427. 1992 .

[9] D.J. Kern, \& K.E. Culley. "How do Submarine Force trainers use computer-based navigation trainer systems? Applying cluster analysis to examine situated objectives in the employment of adaptive CBT". Computers in Human Behavior, Vol. 49, pp. 313-323. 2015.

[10] S. Ghoshal, \& C. Bartlett."Linking organizational context and managerial action: the dimensions of quality of management", Strategic Management Journal, Vol. 15 No. 5, pp. 91-112. 1994.

[11] Z. Belkhamza, Z., \& S.A. Wafa. "Validating the organizational context measure for collective learning: a managerial action perspective". The Learning Organization, Vol 21, No. 4, pp. 222-242 2014.

[12] J. B.Tracey, Tannenbaum, S. I., \& Kavanagh, M. J. "Applying trained skills on the job: The importance of the work environment". Journal of Applied Psychology, Vol. 80, pp. 239-252. 1995.

[13] K.J. Preacher, \& A.F. Hayes, "SPSS and SAS procedures for estimating indirect effects in multiple mediator models." Behavior Research Methods, Instruments, and Computers, Vol. 37, pp. 717-731. 2004. 